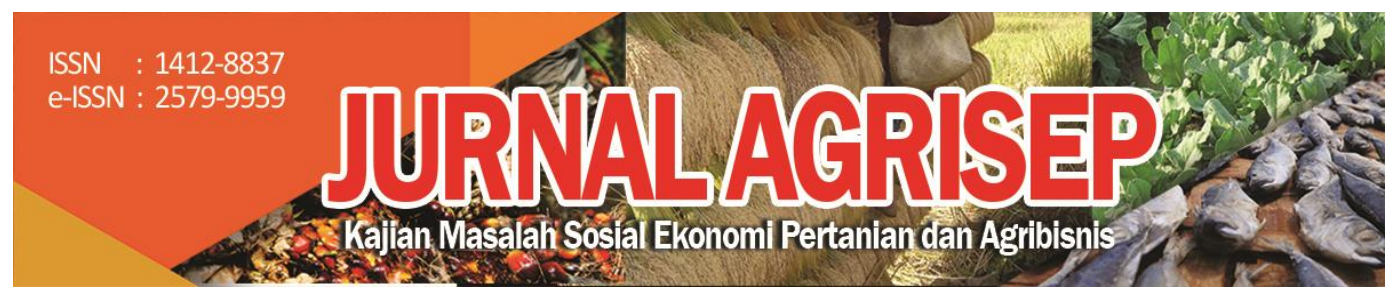

DOI: 10.31186/jagrisep.18.2.371-386

\title{
KEPUASAN PETANI PLASMA KELAPA SAWIT TERHADAP IMPLEMENTASI KEMITRAAN INTI PLASMA
}

\section{Plasma Farmers' Satisfaction on Implementation of Nucleus-Plasma Partnership}

\author{
Windia Deby Pratiwi Sihombing; Andi Irawan $ه$; Agus Purwoko \\ Jurusan Sosial Ekonomi Pertanian Fakultas Pertanian Universitas Bengkulu \\ Email: andiirawan@unib.ac.id
}

\begin{abstract}
The objective of this research analyzed the level of plasma farmers satisfaction on the service performance of Nucleus-Plasma's partnership implementation by PT. Agricinal. The research was conducted in Putri Hijau District of North Bengkulu Regency. Research site is selected purposively. Data were collected at the study site from March to April 2018. Primary data obtained directly through the questionnaire which is given to oil palm farmers and secondary data were obtained from PT. Agricinal. The sampling method used in this study was Simple Random Sampling and 95 farmers selected randomly as samples. Consumer Satisfaction Index was $74.20 \%$ which revealed that smallholders are satisfied with the implementation of the NucleusPlasma partnership. The service attributes to be maintained are quick response service, implementation and guarantee the development of KPEN-RP (Credit for Bio-Energy Development and Plantation Revitalization), provide trained counselor, ensure farmers selling price, technical and non technical guidance, the commitment to buy output (fresh fruit bunches) during the partnership contract, making the layout plan in accordance with the company's estate, ensuring farmers got subsidy of interest of KPEN-RP's credit. The company also must increase the attributes of partnership services namely; 1) the main priority is providing monitoring book on the implementation of partnership to the farmers as a form of transparency in the implementation of partnership contract, and 2) the less important priorities are cattle ownership, development and maintenance of the palm oil farming in accordance with technical standards, cooperatives management was representing farmers in submitting complaints to PT Agricinal, and helped farmers to find sources of another financing.
\end{abstract}


Keywords : partnership, nucleus-plasma, costumer statisfaction index, oil palm

\begin{abstract}
ABSTRAK
Penelitian bertujuan menganalisis tingkat kepuasan petani plasma terhadap kinerja pelayanan Kemitraan Inti Plasma oleh perusahaan PT. Agricinal. Penelitian dilaksanakan di Kecamatan Putri Hijau Kabupaten Bengkulu Utara. Pemilihan lokasi penelitian dilakukan secara purporsive (sengaja). Waktu penelitian dilaksanakan pada bulan Maret - April 2018. Data primer didapat secara langsung melalui kuisioner yang diberikan kepada petani kelapa sawit dan data sekunder didapat dari perusahaan PT. Agricinal. Metode pengambilan sampel yang digunakan dalam penelitian ini adalah Simple Random Sampling dengan sampel sebanyak 95 orang. Indeks Kepuasan Konsumen (Costumer Satisfaction Indeks) sebesar 74.20 \% menunjukkan petani plasma puas terhadap implementasi kemitraan Inti-Plasma. Atribut pelayanan yang perlu dipertahankan adalah pelayanan cepat tanggap, pelaksanaan dan menjamin pengembangan KPEN-RP (Kredit Pengembangan Energi Nabati Dan Revitalisasi Perkebunan), memberikan pembina yang telah dilatih terlebih dahulu, memastikan harga jual yang telah diberikan kepada petani, bimbingan teknis dan non teknis kepada petani, komitmen membeli TBS (Tandan Buah Segar) selama kerjasama berlangsung, pembuatan rencana tataruang sesuai dengan kebun perusahaan, memastikan petani mendapatkan subsidi bunga kredit KPEN-RP. Perusahaan juga harus meningkatkan atribut-atribut pelayanan kemitraan yakni; 1) priotas utama pemberian buku pantauan pelaksanaan kemitraan kepada petani sebagai bentuk transafaransi pelaksanaan kontrak kerja, dan 2) prioritas yang kurang utama yaitu kredit kepemilikan sapi, pembangunan dan pemeliharaan kebun sesuai dengan standar teknis, pengurus koperasi pekebun yang mewakili petani dalam menyampaikan keluhan ke pihak perusahaan, dan membantu mencarikan sumber pembiayaan.
\end{abstract}

Kata kunci: kemitraan, inti-plasma, indeks kepuasan konsumen, kelapa sawit

\title{
PENDAHULUAN
}

Arti penting perkebunan sawit bagi ekonomi rumahtngga petani sawit di Sumatera dapat dilihat dari kontribusi kontribusi terhadap total pendapatan rumahtangga yakni 63-78 persen dari total pendapatan rumahtangga. Data pendapatan perkapita menunjukan pendapatan rumahtangga petani sawit rakyat Sumatera (Rp1,34 juta perbulan perkapita) lebih tinggi dibandingkan dari pendapatan perkapita rumah tangga sawit rakyat di Kalimantan dan Sulawesi (Rp1,22 juta per bulan per kapita) (Irawan, 2018)

Provinsi Bengkulu adalah salah satu provinsi di Sumatera yang mengembangkan perkebunan tanaman kelapa sawit yang menduduki peringkat ke-10 dari luas areal lahan dan produksi kelapa sawit Indonesia (Direktoral Jendral Perkebunan 2016). Luas lahan tanaman perkebunan kelapa sawit yang berada pada provinsi Bengkulu adalah 157.408, 64 hektar dan 
jumlah rumahtangga petani yang terlibat di dalamnya sebanyak 84944 rumahtangga (BPS,2013)

Dalam rangka meningkatkan produktivitas usahatani dan kesejahteraan mereka Indonesia telah menginisiasi bentuk kemitraan antara petani dengan perusahaan perkebunan sawit milik swasta dan Badan Usaha Milik Negara yang dikenal dengan pola kemitraan inti plasma sejak tahun 1969. Salah satu perusahaan perkebunan kelapa sawit yang ada di provinsi Bengkulu yang menjalankan kemitraan inti plasma ini adalah perusahaan PT Agricinal yang berada di Kabupaten Bengkulu Utara.

PT. Agricinal yang berdiri sejak tahun 1981 adalah salah satu perusahaan yang bergerak dalam perkebunan sawit dan mempunyai pabrik pengolahan (Crude Palm Oil) CPO maupun (Palm Kernel Oil) PKO sendiri. Kebun inti dan kebun plasmanya terletak di Kecamatan Putri Hijau Kabupaten Bengkulu Utara Provinsi Bengkulu. Dalam program kemitraan ini, kebun plasma adalah areal kebun yang dibangun dilahan milik petani peserta sedangkan perusahaan membantu menyediakan bibit, bantuan teknis lainnya serta pemasaran hasil produksi petani. Pada saat ini perusahaan telah memberikan bibit tanaman kelapa sawit sebanyak 1.236.905 bibit untuk lahan seluas 11.497 Ha yang tersebar di daerah Bengkulu Utara yang melibatkan 6.312 orang petani plasma yang tersebar di 60 desa.

Menurut Diyahya et.al (2016) dan Fatimah et.al (2016) aspek pelayanan merupakan kinerja yang perlu ditingkatkan dalam keberlangsungan kemitraan. Sedangkan menurut Ritonga (2016) kualitas dan ketepatan waktu dalam pelayanan harus ditingkatkan untuk meningkatkan kepuasan petani. Penelitian (Ramulis, 2014) menunjukan kemitraan inti plasma dilakukan oleh perusahaan PT Agricinal lebih menguntungkan pihak perusahaan dan tidak adanya transparansi mengenai pembiayaan-pembiayaan yang dilakukan oleh perusahaan sehingga dalam pelaksanaannya cenderung merugikan petani plasma. Penelitian Ramulis (2014) tersebut menggunakan metode penelitian kualitatif yang menggunakan informan ( 1 orang petugas legal officer PT Agricinal, 5 orang petani plasma dan 5 orang kelompok tani). Penelitianpenelitian tersebut belum bisa menggeneralisasikan bahwa petani plasma yang menjadi mitra PT Agricinal Bengkulu Utara tidak puas terhadap pelaksanaan kemitraan Inti-Plasma. Oleh karena penting untuk dikaji secara komprehensif; 1) bagaimana sesungguhnya tingkat kepuasan petani plasma terhadap kinerja pelayanan Kemitraan Inti Plasma perusahaan PT. Agricinal. 2) atribut-atribut pelayanan mana yang penting untuk ditingkatkan dan dipertahankan oleh perusahaan dalam rangka menjaga keberlangsungan kemitraan perusahaan dengan petani plasma. 


\section{METODE PENELITIAN}

\section{Lokasi Dan Waktu Pelaksanaan.}

Pemilihan lokasi penelitian dilakukan secara purporsive (sengaja). Kecamatan Putri Hijau dipilih sebagai lokasi penelitian dengan pertimbangan di kecamatan ini tercatat sebanyak 17 desa wilayah mitra perusahaan dengan jumlah anggota petani peserta sebanyak 1.686 orang. Pengumpulan data penelitian dilaksanakan pada Maret - April 2018.

\section{Jenis Dan Sumber Data}

Jenis dan sumber data yang di gunakan dalam penelitian ini adalah data Primer dan data sekunder. Data primer adalah data yang bersifat kuantitatif dan kualitatif yang dibuat berdasarkan perjanjian kemitraan inti plasma antara PT Agricinal dan petani plasma. Data primer dikumpulkan secara langsung melalui kuisioner yang diberikan kepada responden petani kelapa sawit. Rincian pertanyaan terkait kepuasan petani seperti terlihat dalam Tabel 1 . Sedangkan data sekunder berupa catatan atau dokumen-dokumen yang didapat dari perusahaan PT. Agricinal mengenai pelaksanaan kemitraan.

Tabel 1 Atribut pertanyaan tingkat kepentingan dan kinerja kemitraan.

\section{No}

\section{Pertanyaan}

\section{KEANDALAN (Reability)}

$1 \quad$ Apakah anda sudah menerima kebun sesuai dengan standar teknis pembangunan kebun yang ditetapkan oleh departemen pertanian dengan biaya yang dapat dipertangung jawabkan oleh perusahaan?

2 Apakah menurut anda perusahaan sudah melaksanakan penyuluhan kepada petani mitra?

3 Apakah perusahaan sudah melaksanakan pembangunan kebun sesuai dengan standar teknis pembangunan kebun yang ditetapkan oleh kementerian pertanian dengan biaya yang dapat dipertangung jawabkan oleh perusahaan?

\section{DAYA TANGGAP (Responsiveness)}

$4 \quad$ Apakah anda mendapatkan informasi yang transparan meliputi biaya-biaya pembangunan, pengelolahan kebun dan penjualan hasil kebun yang dipertangung jawabkan oleh perusahaan?

5 Apakah perusahaan sudah memberikan pelayanan cepat tanggap terhadap permasalalahan yang dirasakan petani? 


\section{JAMINAN (Ansurance)}

6 Apakah anda sudah mendapatkan bantuan fasilitas kredit untuk kepemilikan sapi yang dijanjikan oleh perusahaan?

7 Apakah perusahaan menjaga agar standar teknis yang sudah ditetapkan kementerian pertanian selalu dipenuhi dengan baik dalam masa pembangunan maupun pemeliharaan kebun?

8 Apakah perusahaan telah menyelengarakan proses pelaksanaan dan menjamin pengembalian KPEN-RP (Kredit Pengembangan Energi Nabati Dan Revitalisasi Perkebunan) kepada petani ?

\section{EMPATI (Emphaty)}

9 Apakah pengurus koperasi mewakili para petani dalam menyampaikan keluhan-keluhan dalam pelaksanaan manajemen oleh perusahaan?

10 Apakah perusahaan memberikan seorang Pembina yang telah mendapatkan pelatihan terlebih dahulu dari perusahaan dengan 25 orang petani yang terdaftar untuk membina secara teknis agar mampu mengusahakan kebun, baik selama masa pembangunan maupun selama tanaman menghasilkan serta memfasilitasi peremajaan tanaman

11 Apakah perusahaan mencarikan sumber pembiayaan untuk fasilitas kredit kepemilikan sapi dan program-program lainnya dalam rangka satu kesatuan manajemen ?.

\section{BUKTI FISIK (Tangibles)}

12 Apakah anda menerima harga jual untuk hasil TBS(Tandan Buah Segar) yang telah diberikan kepada petani. Atau harga kesepakatan antara petani dan perusahaan apabila harga TBS tidak ditentukan oleh pemerintah?

13 Apakah petani memperoleh bimbingan teknis dan non terknis dari perusahaan?

14 Benarkah perusahaan wajib membeli hasil tanam TBS selama perjanjian kerja sama ini berlangsung?

15 Apakah petani memperoleh subsidi bunga kredit KPEN-RP dari pemerintah ?

16 Apakah perusahaan sudah membuat rencana tata ruang kebun yang sesuai dengan standar tata ruang kebuh perusahaan?

17 Apakah perusahaan memberikan buku pantauan implementasi kemitraan?

Sumber : Kontrak kerja pelaksanaan kemitraan inti plasma PT Agricina

Adapun pilihan jawaban dari rincian pertanyaan pada Tabel 1 disajikan ke petani sampel dalam bentuk skala likert seperti yang terlihat pada Tabel 2. 
Tabel 2. Pilihan jawaban terhadap pertanyaan atribut tingkat kepentingan dan kinerja dari implementasi kemitraan Inti-Plasma..

\begin{tabular}{lcl}
\hline \multicolumn{1}{c}{ Tingkat Kepentingan $(\mathrm{Y})$} & Nilai Bobot & \multicolumn{1}{c}{ Tingkat Kinerja $(\mathrm{X})$} \\
\hline Tidak Penting & 1 & Tidak Baik \\
Kurang Penting & 2 & Kurang Baik \\
Cukup Penting & 3 & Cukub Baik \\
Penting & 4 & Baik \\
Sangat Penting & 5 & Sangat Baik \\
\hline Sumber : Yola dan Budianto (2013) & &
\end{tabular}

Sumber : Yola dan Budianto (2013)

\section{Metode Penentuan dan Pengambilan Sampel.}

Populasi petani plasma yang tergabung dalam kemitraan inti plasma dengan PT Agricinal adalah sebanyak 1.686 petani mitra. Dengan teknik penarikan sampel acak sederhana (Simple Random Sampling) dipilih 95 petani plasma sebagai sampel. Jumlah sampel yang diambil dari populasi merujuk pada rumus Slovin (Sujarweni, 2014).

\section{Metode Analisis Data}

Analisis data yang digunakan untuk melihat tingkat kepuasan petani mitra terhadap kinerja kemitraan inti plasma ini adalah dengan menggunakan analisis data IPA (Importance Performance Analysis) dan CSI (Costumer Satisfaction Indeks).

\section{Importance Performance Analysis (IPA)}

Analisis kinerja yang penting (Importance Performance Analysis) adalah analisis yang digunakan untuk mengukur tingkat kepuasan atas kinerja kemitraan Inti-Plasma perusahaan PT Agricinal dengan cara mengukur harapan dan pelaksanaannya. Harapan adalah tingkat kepentingan petani terhadap implementasi semua atribut kontrak perjanjian inti plasma. Tingkat kinerja adalah kinerja aktual dari mutu yang diberikan oleh pihak perusahaaan yang dirasakan oleh petani mitra.

Untuk mengukur tingkat kepentingan dan tingkat kinerja, maka setiap responden diminta dapat merangkingkan seberapa baik tingkat kepentingan dan tingkat kinerja kemitraan Inti-Plasma terhadap Kinerja petani Kelapa Sawit.Untuk dapat menentukan prioritas tingkat kepentingan dan kinerja atribut peneliti menggunakan software SPSS 23.

Adapun rumus tingkat kesesuaian yang digunakan sebagai berikut (Santoso,2011) :

376 | Windia Deby Pratiwi Sihombing; Andi Irawan; Agus Purwoko; .... 


$$
\mathrm{TK}_{i}=\frac{X_{i}}{Y_{i}} \times 100 \%
$$

dimana Tki : Tingkat kesesuaian; Xi : Skor tingkat kinerja; Yi : Skor tingkat kepentingan. Jika nilai Tki $<100 \%$ berarti kinerja atribut belum memenuhi kepuasan petani plasma. Sedangkan jika Tki > 100\% berarti kinerja atribut telah memenuhi kepuasan petani plasma

Selanjutnya, kinerja-kinerja atribut penilaian kepentingan diformulasikan kedalam diagram kartesius. Tingkat kepentingan dan kinerja yang dimasukan kedalam diagram kartesius adalah skor rata-rata responden dengan rumus sebagai berikut:

$$
\overline{\bar{X}}=\frac{\sum X_{i}}{k} \operatorname{dan} \overline{\bar{Y}}=\frac{\sum Y_{i}}{k}
$$

dimana $\overline{\bar{X}}$ adalah rataan skor penilaian kinerja atribut kemitraan; $\overline{\bar{Y}}$ adalah rataan skor penilaian kepentingan pada setiap atribut pelaksanaan kemitraan; dan $\mathrm{k}$ adalah banyaknya jumlah yang mempengaruhi kepuasan petani plasma.

Setiap atribut yang telah diperoleh nilai rata-ratanya kemuadian diposisikan pada Diagram Cartesius sebagai berikut (Rangkuti, 2003):

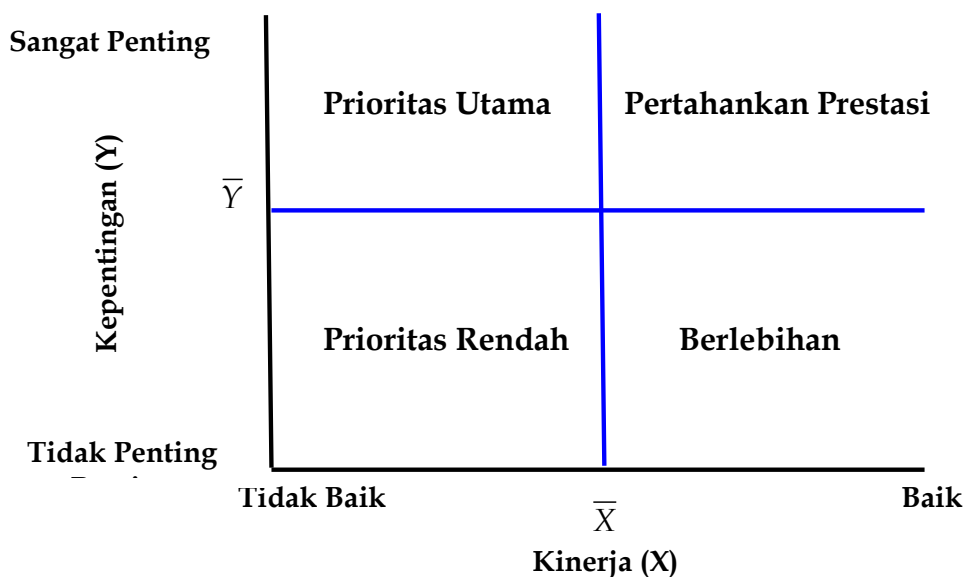

Gambar 2.

Diagaram Importance Performance Analysis (IPA)

Keterangan :

a. Kuadran I (Prioritas Utama) menunjukan atribut yang dianggap penting oleh petani dan kinerja oleh perusahaan belum baik

b. Kuadran II (Pertahankan Prestasi) menunjukan atribut yang dinggap penting oleh petani, dan kinerja oleh perusahaan sudah baik. 
c. Kuadran III (Prioritas Rendah) menunjukan atribut yang di anggap kurang penting oleh petani dan kinerja perusahaan masih rendah.

d. Kuadran IV (Berlebihan) menunjukan atribut yang di anggap kurang penting oleh petani, dan kinerja oleh perusahaan berlebihan.

\section{Customer Satisfaction Indeks (CSI)}

Menurut Santoso (2006), CSI atau indeks kepuasan Konsumen adalah sebuah angka yang menyatakan seberapa besar tingkat kepuasan konsumen/Petani terhadap kemitraan Inti-Plasma. Berikut merupakan tahapan-tahapan dalam pengukuran CSI, yaitu :

a. Menghitng weight-factors (WF) dari tingkat kepentingan atau mean Important score (MIS). Bobot ini merupakan persentase nilai MIS per atribut terhadap total MIS seluruh atribut .

Rumus: $W F=\frac{M I S}{\text { Total MIS }}$

b. Menghitung weighted score (WS), yaitu menilai perkalian antara Nilai rata-rata tingkat kinerja atau mean statisfaction score (MSS), masingmasing atribut dengan WF masing-masing atribut.

Rumus :WS = MSS X WF

c. Menghitung weighted total (WT), Yaitu menjumlahkan semua WS dari semua produk.

d. Menghitung statisfaction indeks, yaitu WT dibagi skala maksimum atau skala tertinggi/highest scale (HS) yang digunakan dalam (penelitian ini skala maksimal adalah 5), kemudian dikali $100 \%$.

Rumus : $C S I=\frac{W A T}{H S} \times 100 \%$

Tingkat Kepuasan petani secara keseluruhan dapat dilhat dari kriteria tingkat kepuasan konsumen, dengan nilai CSI sebagai berikut (Panjaitan 2017)
a. $0 \%<\mathrm{CSI} \leq 20 \%=$ Tidak Puas
b. $21 \%<\mathrm{CS} \mathrm{I} \leq 40 \%=$ Kurang Puas
c. $41 \%<\mathrm{CSI} \leq 60 \%=$ Cukup Puas
d. $61 \%<\mathrm{CSI} \leq 80 \%=$ Puas
e. $81 \%<\mathrm{CSI} \leq 100 \%=$ Sangat Puas 


\section{HASIL DAN PEMBAHASAN}

\section{Tingkat Kesesuaian Petani Plasma Terhadap Pelayanan Kemitraan.}

Tingkat kesesuaian merupakan hasil perbandingan antara skor kinerja dan kepentingan. Dengan menggunakan perhitungan ini dapat melihat skala prioritas layanan dan kinerja untuk dapat melihat kepuasan pelanggan (Yola dan Budianto, 2013). Tingkat kesesuian menunjukan dapat menunjukan bagaimana kinerja yang dilakukan sesuai dengan harapan petani plasma. Berdasarkan tabel 3 dapat diketahui bahwa tingkat kesesuaian setiap dimensi menunjukan rata-rata di atas 100 \% atau 103,61 yang berarti bahwa kinerja pelayanan yang diberikan oleh perusahaan inti berjalan sesuai dengan apa yang diharapkan oleh petani plasma.

Tabel 3. Perhitungan Rata-Rata Penilaian Tingkat Kinerja, Tingkat Kepentingan Dan Tingkat Kesesuain.

\begin{tabular}{|c|c|c|c|c|}
\hline No & Atribut & Kepentingan & Kinerja & $\begin{array}{c}\text { Tingkat } \\
\text { Kesesuaian }\end{array}$ \\
\hline \multicolumn{5}{|c|}{ Keandalan (Reability) X1 } \\
\hline 1 & $\begin{array}{l}\text { Penerimaan kebun sesuai dengan } \\
\text { standar tenis }\end{array}$ & 3,49 & 3,71 & 106,0 \\
\hline 2 & $\begin{array}{l}\text { Sudah memberi penyuluhan ke } \\
\text { petani }\end{array}$ & 3,60 & 3,75 & 104,1 \\
\hline 3 & $\begin{array}{l}\text { Sudah melaksanakan pembangunan } \\
\text { kebun sesuai dengan standar teknis }\end{array}$ & 3,53 & 3,78 & 107,2 \\
\hline & Rata-rata variabel $\mathrm{X} 1$ & 3,54 & 3,74 & 105,76 \\
\hline \multicolumn{5}{|c|}{ Daya Tanggap (Responsiveness) X2 } \\
\hline 4 & $\begin{array}{l}\text { Mendapatkan informasi yang } \\
\text { transparan }\end{array}$ & 3,58 & 3,97 & 110,9 \\
\hline 5 & Pemberian pelayanan cepat tanggap & 3,63 & 3,71 & 102,0 \\
\hline & Rata-rata variabel X2 & 3,61 & 3,84 & 106,46 \\
\hline \multicolumn{5}{|c|}{ Jaminan (Ansurance) X3 } \\
\hline 6 & $\begin{array}{l}\text { Mendapatkan fasilitas kredit } \\
\text { kepemilikan sapi }\end{array}$ & 3,49 & 3,55 & 101,5 \\
\hline 7 & $\begin{array}{l}\text { Menjaga dan memenuhi masa } \\
\text { pembangunan dan pemeliharaan } \\
\text { sesuai standar teknis }\end{array}$ & 3,52 & 3,68 & 104,8 \\
\hline 8 & $\begin{array}{l}\text { Menjamin pengembalian biaya } \\
\text { KPEN-RP }\end{array}$ & 3,63 & 3,78 & 104,1 \\
\hline & Rata-rata Variabel X3 & 3,55 & 3,67 & 103,45 \\
\hline
\end{tabular}




\begin{tabular}{|c|c|c|c|c|}
\hline \multicolumn{5}{|c|}{ Emphati (Emphaty) X4 } \\
\hline 9 & $\begin{array}{l}\text { Koperasi mewakili petani dalam } \\
\text { penyampaian keluhan }\end{array}$ & 3,55 & 3,65 & 103,0 \\
\hline 10 & $\begin{array}{l}\text { Memberikan Pembina yang telah } \\
\text { dilatih terlebih dahulu }\end{array}$ & 3,68 & 3,79 & 102,9 \\
\hline 11 & $\begin{array}{l}\text { Perusahaan mencarikan sumber } \\
\text { pembiayaan }\end{array}$ & 3,60 & 3,64 & 101,2 \\
\hline & Rata-rata Variabel X4 & 3,61 & 3,69 & 102,33 \\
\hline \multicolumn{5}{|c|}{ Bukti Fisik (Tangible) X5 } \\
\hline 12 & $\begin{array}{l}\text { Menerima harga jual yang telah } \\
\text { diberikan kepada petani }\end{array}$ & 3,61 & 3,72 & 102,9 \\
\hline 13 & $\begin{array}{l}\text { Memperolah bimbingan teknis dan } \\
\text { Non teknis }\end{array}$ & 3,64 & 3,71 & 101,7 \\
\hline 14 & $\begin{array}{l}\text { Perusahaan wajib membeli hasil } \\
\text { tanam TBS selama kerjasama }\end{array}$ & 3,78 & 3,83 & 101,4 \\
\hline 15 & $\begin{array}{l}\text { Perusahaan menbuat rencana tata } \\
\text { ruang sesuai dengan kebun } \\
\text { perusahaan }\end{array}$ & 3,66 & 3,72 & 101,4 \\
\hline 16 & $\begin{array}{l}\text { Petani mendapatkan subsidi bunga } \\
\text { kredit KPEN-RP }\end{array}$ & 3,68 & 3,74 & 101,4 \\
\hline 17 & $\begin{array}{l}\text { Memberikan buku pantauan } \\
\text { pelaksanaan kemitraan. }\end{array}$ & 3,65 & 3,65 & 100,0 \\
\hline & Rata-rata Variabel X5 & 3,67 & 3,73 & 101,48 \\
\hline & Rata-rata & 3.60 & 3,73 & 103,61 \\
\hline
\end{tabular}

Sumber: Olahan Data Primer 2018.

Dari Tabel 3, rata-rata tingkat kepentingan pada sumbu $\overline{\bar{Y}}$ sebesar 3,60 dan rata-rata tingkat kinerja pada sumbu $\overline{\bar{X}}$ sebesar 3,73. Berdasarkan nilai rata-rata dari setiap variabel kepentingan dan kinerja akan digunakan untuk mengambarkan diagram katesius. Diagram ini dibagi dalam empat bagian kuadaran ke-1 merupakan prioritas utama, bagian kedua kuadran ke-2 merupakan area pertahankan prestasi, bagian ketiga atau kuadran ke-3 merupakan prioritas rendah, dan bagian keempat (kuadran ke-4) merupakan prioritas berlebihan.

Diagram kartesius merupakan diagram yang digunakan untuk mengetahui kualitas pelayanan. Diagram ini digunakan untuk mengidentifikasi langkah-langkah perbaikan melalui peningkatan pada pelayanan yang diberikan. Berdasarkan nilai dari tingkat kepentingan dan tingkat kinerja keduanya dimasukan kelalam diagram kartesius dimana sumbu $X$ merupakan sumbu tingkat kinerja pelayanan perusahaan dan sumbu $Y$ merupakan tingkat kepentingan petani terhadap pelayanan tersebut. 
Berdasarkan gambar diagram kartesius di atas dapat dikeatahui atribut setiap kuadran yakni sebagai berikut :

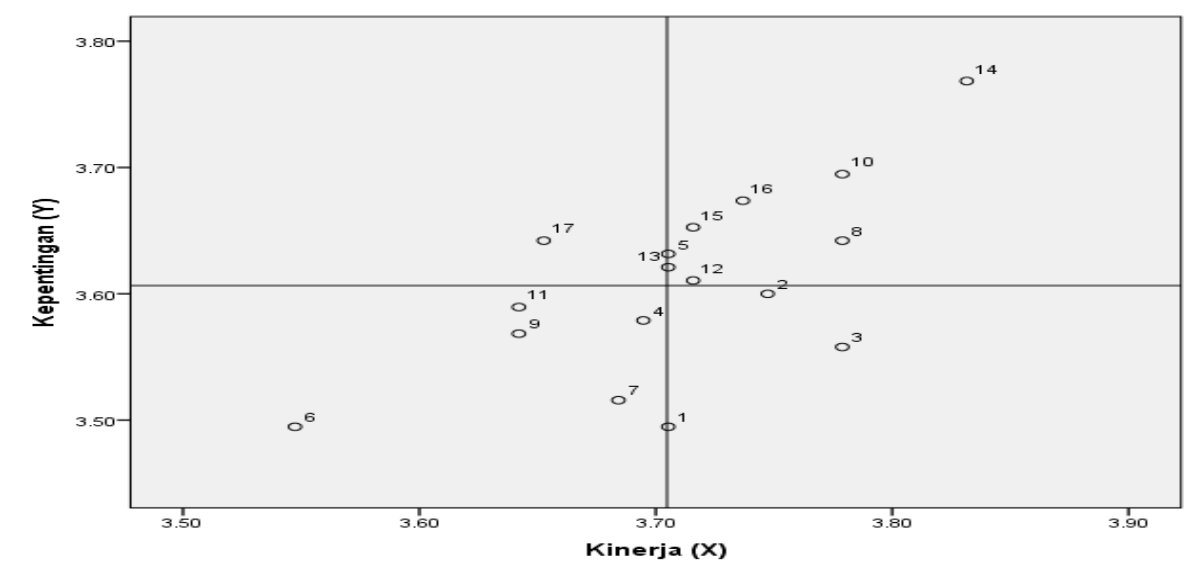

Gambar 1.

Diagram Kartesius Importance Performance Analisis.

Keterangan atribut :

1 Penerimaan kebun sesuai dengan standar tenis

2 Sudah menerima penyuluhan ke petani

3 Sudah melaksanakan pembangunan kebun sesuai dengan standar teknis

4 Mendapatkan informasi yang transparan

5 Pemberian pelayanan cepat tanggap

6 Mendapatkan fasilitas kredit kepemilikan sapi

7 Menjaga dan memenuhi masa pembangunan dan pemeliharaan sesuai standar teknis

8 Pelaksanaan dan menjamin pengembalian kredit KPEN-RP (Pengembangan Energy Nabati Dan Revitalisasi Perkebunan)

9 Koperasi mewakili petani dalam penyampaian keluhan
10 Memberikan pembina yang telah dilatih terlebih dahulu

11 Perusahaan mencarikan sumber pembiayaan

12 Menerima harga jual yang telah diberikan kepada petani

13 Memperolah bimbingan teknis dan non teknis

14 Perusahaan wajib membeli hasil tanam TBS selama kerjasama

15 Perusahaan membuat rencana tata ruang sesuai dengan kebun perusahaan

16 Petani mendapatkan subsidi bunga kredit KPEN-RP (Pengembangan Energy Nabati Dan Revitalisasi Perkebunan)

17 Memberikan buku kepada petani (pantauan pelaksanaan kemitraan) 


\section{Kuadran I (Prioritas Utama)}

Pada kuadran Prioritas Utama merupakan wilayah yang membuat atribut-atribut yang dianggap penting oleh petani tapi pelayanan yang diberikan oleh perusaahan masih dibawah standar. Yang menjadi atribut prioritas utama adalah atribut nomor 17 yaitu perusahaan perlu meningkatkan pemberian buku pantauan kepada petani. Buku yang dimaksud adalah buku mengenai budidaya tanaman kelapa sawit, dan buku panduan pelaksanaan mengenai kemitraan inti plasma yang sudah disediakan oleh perusahaan, pelaksanaan kontrak atau perjanjian tentang kemitraan. Diagram ini menunjukan bahwa petani menganggap pemberian buku kepada petani dianggap penting dan perusahaan harus meningkatkan atribut ini untuk keberlangsungan pelaksanaan kemitraan dan usaha tani karena buku ini menunjukkan transfaransi pelaksanaan kemitraan oleh perusahaan kepada petani plasma. Hasil penelitian ini selaras dengan temuan Ramulis (2014) yang mengatakan pola kemitraan Inti Plasma PT Agricinal lebih menguntungkan perusahaan dikarenakan tidak adanya transfaransi dalam pelaksanaannya.

\section{Kuadran II (Pertahankan Prestasi)}

Kuadran pertahankan prestasi merupakan wilayah yang diaggap penting oleh petani dan petani merasa senang dan puas terhadap atribut pelayanan ini. Dengan demikian pelayanan atribut-atribut ini harus dipertahankan kinerjanya oleh perusahaan. Yang menjadi atribut pada kuadran pertahankan prestasi adalah atribut 5 (memberikan pelayanan cepat tanggap), 8 (pelaksanaan dan menjamin pengambangan KPEN-RP), 10 (memberikan pembina yang telah dilatih terlebih dahulu), 12 (menerima harga jual yang telah diberikan kepada petani), 13 (memperoleh bimbingan teknis dan non teknis kepada petani), 14 (perusahaan wajib membeli TBS selama kerjasama berlangsung), (15 perusahaan membuat rencana tataruang sesuai dengan kebun perusahaan), dan 16 (petani mendapatkan subsidi bunga kredit KPEN-RP). Dengan demikian atribut-atribut tersebut merupakan atribut yang menjadi keungulan pelayanan perusahaan untuk keberlangsungan pelaksanaan kemitraan yang harus dipertahankan perusahaan.

\section{Kuadran III (Prioritas Rendah)}

Kuadran prioritas rendah merupakan kuadran wilayah kuadran yang kinerjanya kurang dan petani tidak menganggap penting atribut ini. Yang menjadi kinerja atribut-atribut yang berada pada kuadran ini adalah atribut 4 (mendapatkan informasi yang transparan), 6 (mendapatkan kredit kepemilikan sapi), 7 (menjaga dan memenuhi masa pembangunan dan pemeliharaan sesuai dengan standar teknis), 9 (pengurus koperasi mewakili petani dalam menyampaikan keluhan), dan 11 (perusahaan mencarikan sumber 
pembiayaan). Walaupun prioritas rendah untuk keberlangsungan jangka panjang kemitraan perusahaan perlu meningkatkan kinerja layanan pada astribut-atribut tersebut.

\section{Kuadran IV (Prioritas Berlebihan)}

Kuadran prioritas berlebihan menunjukan atribut-atribut yang dianggap kurang penting namun kinerja pelayanan perusahaan dinilai memuaskan. Atribut pelayanan yang termasuk kedalam kategori ini adalah atribut 1 (menerima kebun sesuai dengan standar teknis), 2 (sudah menerima peyuluhan), 3 (sudah melaksanakan pembangunan kebun sesuai dengan standar teknis).

\section{Pengukuran tingkat kepuasan petani dengan menggunakan Costumer Satisfaction Indeks (CSI).}

Pengukuran terhadap costumer satisfaction indeks (CSI) merupakan pengukuran yang digunakan untuk mengetahui besarnya indeks kepuasan yang dihasilkan oleh suatu pelayanan. Pengukuran kepuasan digunakan untuk mengukur besarnya harapan yang dipenuhi oleh pihak perusahaan. Indeks kepuasan digunakan untuk menentukan sasaran yang akan datang. Dengan menggunakan indeks kepuasan maka perusahaan dapat menentukan target dalam peningkatan kepuasan petani plasma. Tingkat kepuasan petani plasma terhadap kemitraan dapat dilihat pada tabel berikut :

Tabel 4. Nilai tingkat CSI kepentingan dan kinerja pelayanan kemitraan inti plasma.

\begin{tabular}{ccccc}
\hline $\begin{array}{c}\text { No } \\
\text { Atribut }\end{array}$ & $\begin{array}{c}\text { Rata-Rata Kepentingan } \\
\text { (MIS) }\end{array}$ & $\begin{array}{c}\text { Wight Factor } \\
\text { (WF) }\end{array}$ & $\begin{array}{c}\text { Rata-Rata Kinerja } \\
\text { (MSS) }\end{array}$ & Weight Score \\
\hline 1 & 3.49 & 5.70 & 3.71 & 0.21 \\
2 & 3.60 & 5.87 & 3.75 & 0.22 \\
3 & 3.56 & 5.80 & 3.78 & 0.22 \\
4 & 3.58 & 5.83 & 3.69 & 0.22 \\
5 & 3.63 & 5.92 & 3.71 & 0.22 \\
6 & 3.49 & 5.70 & 3.55 & 0.20 \\
7 & 3.52 & 5.73 & 3.68 & 0.21 \\
8 & 3.64 & 5.94 & 3.78 & 0.22 \\
9 & 3.57 & 5.82 & 3.64 & 0.21 \\
10 & 3.69 & 6.02 & 3.78 & 0.23 \\
11 & 3.59 & 5.85 & 3.64 & 0.21 \\
12 & 3.61 & 5.89 & 3.72 & 0.22 \\
13 & 3.62 & 5.90 & 3.71 & 0.22 \\
\hline
\end{tabular}




\begin{tabular}{|c|c|c|c|c|}
\hline $\begin{array}{c}\text { No } \\
\text { Atribut }\end{array}$ & $\begin{array}{c}\text { Rata-Rata } \\
\text { Kepentingan (MIS) }\end{array}$ & $\begin{array}{c}\text { Wight Factor } \\
(\mathrm{WF})\end{array}$ & $\begin{array}{c}\text { Rata-Rata Kinerja } \\
\text { (MSS) }\end{array}$ & Weight Score \\
\hline 14 & 3.77 & 6.14 & 3.83 & 0.24 \\
\hline 15 & 3.65 & 5.95 & 3.72 & 0.22 \\
\hline 16 & 3.67 & 5.99 & 3.74 & 0.22 \\
\hline 17 & 3.64 & 5.94 & 3.65 & 0.22 \\
\hline TOTAL & 61.34 & 99.99 & 63.06 & 3.71 \\
\hline \multicolumn{5}{|c|}{ Weighted Total } \\
\hline
\end{tabular}

Sumber: Olahan Data Primer 2018.

Keterangan : MIS :Mean importance score; WF : weight factor = (MIS/61.34) MSS :Mean satisfaction score dan WS :Weight score $=($ MSS $\times$ WF $) / 100$

Berdasarkan Tabel 6, indeks kepuasan petani plasma terhadap kinerja kemitraan inti plasma sebesar 74,20\%. Angka ini berarti petani plasma merasa puas terhadap kinerja kemitraan inti plasma PT Agricinal.

\section{SIMPULAN DAN SARAN}

\section{Simpulan}

Kesimpulan penelitian ini adalah sebagai berikut :

1) Indeks Kepuasan Konsumen (Constumer Statisfaction Indeks) CSI sebesar $74.20 \%$ menunjukkan petani plasma puas terhadap implementasi kemitraan Inti-Plasma.

2) Atribut pelayanan kemitraan yang perlu dipertahankan adalah pelayanan cepat tanggap, pelaksanaan dan menjamin pengembangan KPEN-RP, memberikan pembina yang telah dilatih terlebih dahulu, memastikan harga jual yang telah diberikan kepada petani, bimbingan teknis dan non teknis kepada petani, komitmen membeli TBS selama kerjasama berlangsung, pembuatan rencana tataruang sesuai dengan kebun perusahaan, memastikan petani mendapatkan subsidi bunga kredit KPEN-RP. Perusahaan juga harus meningkatkan atribut-atribut pelayanan kemitraan yakni; 1) priotas utama pemberian buku pantauan pelaksanaan kemitraan kepada petani sebagai bentuk transafaransi pelaksanaan kontrak kerja, dan 2) prioritas yang kurang utama yaitu kredit kepemilikan sapi, pembangunan dan pemeliharaan kebun sesuai dengan standar teknis, pengurus koperasi pekebun yang mewakili petani dalam menyampaikan keluhan ke pihak perusahaan, dan membantu mencarikan sumber pembiayaan. 


\section{Saran}

Perusahan Inti (PT.Agricinal) harus melakukan perbaikan kualitas pelayanan guna untuk meningkatkan kepuasan yang dirasakan oleh petani. Kualitas pelayanan yang paling penting bagi petani yang harus di tingkatkan adalah pemberian buku pantauan pelaksanaan kemitraam agar petani bisa ikut menilai pelaksanaan kemitraan apakah sudah berjalan sesuai dengan kontrak.

\section{DAFTAR PUSTAKA}

Alima Panjaitan, Redy Badrudin dan Agus Purwoko. 2017. Tingkat Analisis Kepuasan Dan Loyalitas Konsumen Produk Roti Kacang Cap Rajawali Di Kota Tebing Tinggi Sumatera Utara. Skripsi. Universitas Bengkulu.

Andi Irawan. 2018. Dampak keberadaan infrastruktur terhadap peningkatan produk dan luas lahan sawit. Agrisep.17(1) 51-62. DOI: https://doi.org/10.31186/jagrisep.17.1.51-62

BPS (Badan Pusat Statistik), 2013. Data Sensus Pertanian 2013.Jakarta (ID). Badan Pusat Statistik.

Diyahya, Irvan, Ketut Sukiyono, dan Redy Badrudin. 2016. Analisis Tingkat Kepuasan Petani Jagung Terhadap Pelayanan Lembaga Pemasarannya Di Kecamatan Lubuk Pinang Kabupaten Muko-Muko. Agrisep 16(1): 45-58. DOI: https://doi.org/10.31186/jagrisep.15.1.45-58

Fatimah, Siti, Basuki Sigit Priyono, dan Witman Rasyid. 2016. Analisis Tingkat Kepuasan Konsumen Terhadap Pelayanan Usaha Benih Padi Cigeulis Dibalai Induk Padi dan Palawijaya di Kabupaten Kepahiang Provinsi Bengkulu. $\quad$ Agrisep 15(2): 203-212. DOI: https:// doi.org/10.31186/jagrisep.15.2.203-212

Freddy Rangkuti. 2003. Measuring Constumer Statifaction. Jakarta (ID). PT Gramedia PustakaUtama.

Imam Santoso 2011. Presepsi Konsumen Terhadap Kualitas Bakpao Telo Dengan Metode Importance Performance Analysis (IPA). Jurnal Teknologi Pertanian. 12(1) : 23-30

Melfa Yola dan Duwi Budianto. 2013. Analisis Kepuasan Konsumen Terhadap Kualitas Pelayanan dan Harga Produk Pada Supermarkert dengan Menggunakan Metode Importance Performance Analisis.Jurnal Optimasi System Industri. 12(2): 301-309.

Nasrun Subuh Ritonga. 2016. Analisis Tingkat Kepuasan Petani Petani Di Desa Pir Trans Sosa IV Terhadap Kinerja Penyuluhan Petanian Pada Balai Penyuluh Kecamatan Hutaraja Tinggi Kabupaten Padang Lawas Provinsi Sumatera Utara. eJournal Mahasiswa Fakultas Pertanian 3(6):1-10. 
Ramulis, Herawan Sauni, dan Emelia Kontesa. 2014.Perjajanjian Inti Plasma Antara Perusahaan Inti Plasma Dengan Petani Plasma Dalam Bidang Agribisnis Kelapa Sawit Di PT Agricinal Bengkulu Utara Dikaji Dari Aspek Keseimbangan Para Pihak. Thesis Master. Universitas Bengkulu.

Singgih Santoso, 2006. Seri Solusi Berbasis TI: Menggunkan SPSS dan Excel Untuk Mengukur Sikap Dan Kepuasan Konsumen. Jakarta. PT Elex Mediakomputindo,

Wiratna Sujarweni. 2014. Metodologi Penelitian : Lengkap, Praktis dan Mudah Dipahami. Yogyakarta. Pustaka Baru Press. 